\title{
Infartos placentarios y trombofilias
}

\author{
Placental infarcts and thrombophilias \\ Infartos da placenta e trombofilias
}

Juan Zunino ORCID: 0000-0003-4429-2829 Agregado Clínica Médica A. Facultad de Medicina. UdelaR.

Resumen: En la clasificación actual de las lesiones placentarias, se describen más de un tipo de infarto placentario y otras lesiones de mala perfusión placentaria tanto maternas como fetales. Estas distintas lesiones (procesos vasculares, inflamatorios, inmunes, etc) están incorporadas a los criterios diagnósticos del Grupo de Trabajo Placentario de Amsterdam 2014. En las mismas debe considerarse el estudio de trombofilias adquiridas, sin embargo no existe suficiente evidencia para el estudio de las trombofilias hereditarias. Se realiza una revisión sobre las mismas vinculadas a esta patología.

Palabras clave: infarto placentario, trombofilias.

Abstract: In the current classification of placental lesions, more than one type of placental infarction and other maternal and fetal placental malperfusion lesions are described. These different lesions (vascular, inflammatory, immune processes, etc.) are incorporated into the diagnostic criteria of the Amsterdam Placental Working Group 2014. In them, the study of acquired thrombophilias must be considered, however there is not enough evidence to study the hereditary thrombophilias. A review is carried out on them related to this pathology.

Key words: placental infarction, thrombophilias.

Resumo: Na classificação atual de lesões placentárias, são descritos mais de um tipo de infarto placentário e outras lesões de má perfusão placentária materna e fetal. Essas diferentes lesões (vasculares, inflamatórias, processos imunológicos, etc.) são incorporadas aos critérios diagnósticos do Amsterdam Placental Working Group 2014. Nestes, o estudo das trombofilias adquiridas deve ser considerado, porém não há evidências suficientes para estudar as hereditárias trombofilias. É realizada uma revisão sobre eles relacionados a esta patologia.

Palavras-chave: infarto placentário, trombofilias. 
En la revisión del tema del año $2014^{1}$ se señaló, que en los criterios clasificatorios del Síndrome antifosfolipídico $(\mathrm{SAF})^{2}$ se planteaba "hallazgos reconocidos de insuficiencia placentaria" pero no se hacía mención a ningún tipo de lesión histopatológica placentaria. Si bien se han planteado modificaciones a estos criterios, los mismos siguen vigentes en la actualidad ${ }^{3,4}$. Aún no contamos con guías para la toma de decisiones en cuanto a estudios y terapéutica en situaciones de Infarto placentario.

Basados en los estudios recogidos ${ }^{5,6}$, concluimos que en presencia de infarto placentario y mala historia obstétrica debe considerarse el estudio de SAF. Respecto a las trombofilias hereditarias señalamos la ausencia de evidencia para realizar su estudio.

De la presente revisión debemos destacar el progreso realizado respecto a la clasificación de los criterios diagnósticos placentarios, existiendo gradual aceptación de un sistema estandarizado, reproducible y con bases biológicas. Es así que, en la clasificación actual de las lesiones placentarias, se describen más de un tipo de infarto placentario y otras lesiones de mala perfusión placentaria tanto maternas como fetales ${ }^{7}$. De lo anterior se desprende la complejidad del eventual vínculo de estas lesiones con diferentes trombofilias hereditarias o adquiridas.

En la tabla 1 se presenta la clasificación actualizada de los diferentes diagnósticos placentarios, que incorporan los criterios del Grupo de Trabajo Placentario de Amsterdam 2014 .

\begin{tabular}{|c|}
\hline 1. Procesos Vasculares placentarios \\
\hline a. LESIONES VASCULARES-ESTROMALES MATERNAS \\
\hline - Del Desarrollo \\
\hline $\begin{array}{l}\text { Implantación superficial/arteriopatía decidual } \\
\text { Incremento del Trofoblasto extravelloso inmaduro }\end{array}$ \\
\hline - Mala perfusión \\
\hline $\begin{array}{l}\text { Global-Parcial • Temprana: hipoplasia vellositaria distal } \\
\text { • Tardía: maduración vellositaria acelerada }\end{array}$ \\
\hline Segmentaria-Completa $\bullet$ Infarto(s) vellositarios \\
\hline - Pérdida de integridad \\
\hline $\begin{array}{l}\text { Abruptio placenta (arterial) } \\
\text { Abruptio marginal (venoso): • Agudo •Crónico }\end{array}$ \\
\hline b. LESIONES VASCULARES-ESTROMALES FETALES \\
\hline - Del Desarrollo \\
\hline $\begin{array}{l}\text { Lesiones capilares vellositarias } \\
\text { Retraso de maduración vellositaria (defecto de maduración) } \\
\text { Vellosidades dismórficas }\end{array}$ \\
\hline - Mala perfusión * \\
\hline $\begin{array}{l}\text { Global-parcial • Lesiones obstructivas del cordón umbilical } \\
\text { - Fibrina intramural reciente en grandes vasos fetoplacentarios } \\
\text { - Focos pequeños de vellosidades avasculares o cariorrécticas }\end{array}$ \\
\hline $\begin{array}{l}\text { Segmentaria-Completa • Trombos de la placa coriónica o de los tallos vellositarios } \\
\text { - Focos grandes de vellosidades avasculares o cariorrécticas }\end{array}$ \\
\hline - Pérdida de integridad \\
\hline $\begin{array}{l}\text { Rotura de grandes vasos (hemorragia fetal) } \\
\text { Rotura de pequeños vasos (hemorragia fetomaterna) } \\
\text { Edema vellositario }\end{array}$ \\
\hline 2. Procesos placentarios inflamatorios-inmunes \\
\hline a. Lesiones infecciosas inflamatorias \\
\hline - Agudas \\
\hline $\begin{array}{l}\text { Respuesta inflamatoria materna: corioamnionitis, subcorionitis } \\
\text { Respuesta inflamatoria fetal: vasculitis coriónica/umbilical }\end{array}$ \\
\hline - Crónicas \\
\hline $\begin{array}{l}\text { Inflamación vellositaria (CMV, otros) } \\
\text { Inflamación Intervillositaria (malaria, otras) }\end{array}$ \\
\hline b. Lesiones inflamatorias inmunes/idiopáticas \\
\hline
\end{tabular}


Tabla 1: Criterios Diagnósticos Placentarios (Incorporando los criterios del Grupo de Trabajo Placentario de Amsterdam 2014) ${ }^{7}$

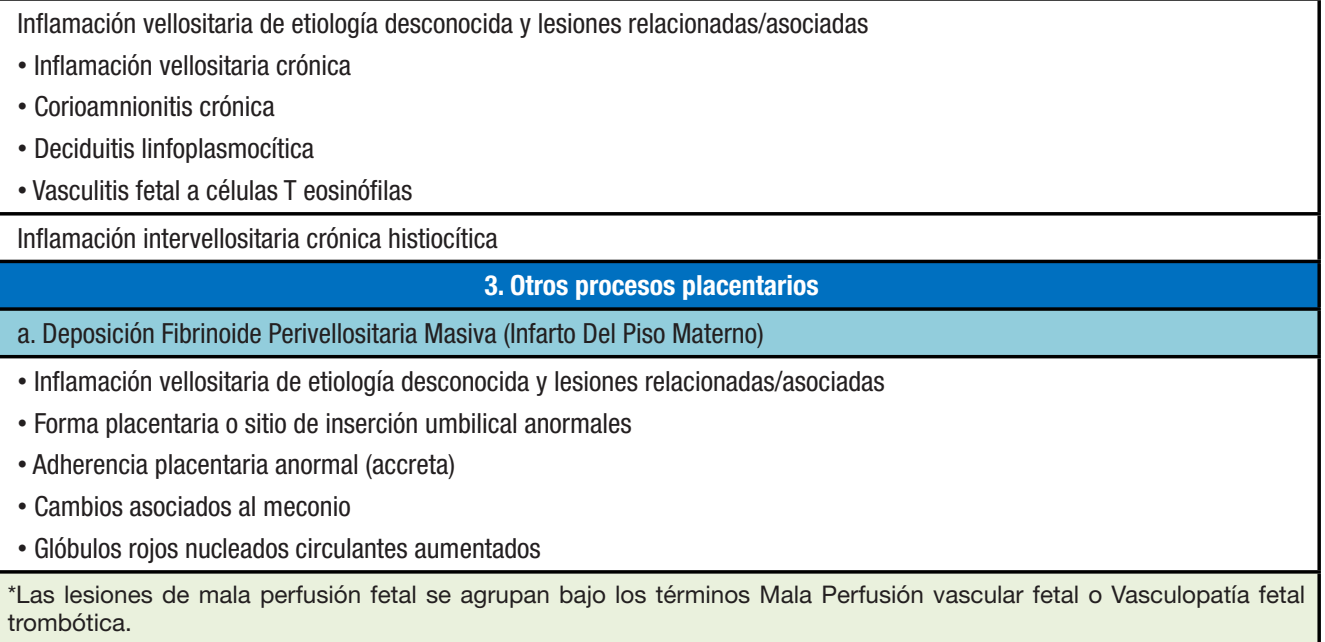

Respecto al SAF obstétrico, varios autores señalan al infarto placentario como uno de sus mecanismos patogénicos ${ }^{3-9}$. Viall et al. realizaron una revisión sistemática acerca de la histopatología placentaria en mujeres con anticuerpos antifosfolipídicos ${ }^{10}$. De los 44 hallazgos histopatológicos reportados en 580 placentas de mujeres con positividad para anticuerpos antifosfolípidos, 6 se objetivaron más frecuentemente comparados con un grupo control. Entre los mismos se encuentra el infarto placentario; alteración de la remodelación de las arterias espirales, inflamación decidual, nudos sinciciales aumentados, disminución de membranas vásculo-sinciciales y depósitos de fracción del complemento C4d ${ }^{10}$.

Respecto a las trombofilias hereditarias, dos revisiones señalan la asociación de mal perfusión vascular fetal con trombofilia hereditaria ${ }^{11,12}$. Otra Revisión, señala la asociación del infarto del piso materno y deposición de fibrina perivellositaria masiva con trombofilia hereditaria así como con anticuerpos antifosfolípidos ${ }^{9}$. Dos de estas revisiones citan el estudio de Gogia y Machin ${ }^{13}$. Estos autores estudiaron trombofilias hereditarias y adquiridas en pacientes con infarto del piso materno (IPM), deposición de fibrina perivellositaria masiva (DFPM), y vasculopatía fetal trombótica (VFT) (40, 87 y 7 casos respectivamente). Además, existieron 4 casos de DFPM más VFT. Las trombofilias fueron identificadas en $16(40 \%), 20(23 \%), 5(71 \%)$, y 2 (50\%), respectivamente. $67 \%$ de las trombofilias fueron hereditarias y $23 \%$ adquiridas (anticuerpos anticardiolipinas e inhibidor lúpico). La trombofilia más frecuente fue el déficit de proteína $S$, que se constató en 39\%. También se constataron déficit de Antitrombina y Factor V Leiden. Estos autores concluyen que deben estudiarse en forma completa las trombofilias en pacientes con las histopatologías antedichas ${ }^{13}$.

En nuestra revisión previa ${ }^{1}$ recogimos varios estudios con evidencia discrepante ${ }^{14-17}$.

Como conclusión señalamos nuevamente la ausencia de guías para toma de decisiones en cuanto a estudios de trombofilia ni terapéutica en situaciones de Infarto placentario y/u otras alteraciones histopatológicas placentarias. Con respecto a los anticuerpos antifosfolípidos algunos expertos opinan que deberían solicitarse los mismos en casos de infartos placentarios basándose en la evidencia disponible.

\section{Recomendaciones}

No hay evidencia de calidad para realizar una recomendación ni sobre los estudios a solicitar ni sobre eventuales tratamientos.

En situaciones individualizadas, se podría considerar el estudio de anticuerpos antifosfolípidicos. 


\section{Bibliografía}

1- Universidad de la República; Facultad de Medicina; Cátedra de Hematología. Trombofilia y Mujer. Montevideo: Fmed; 2014.

2- Miyakis S, Lockshin MD, Atsumi T, Branch DW, Brey RL, Cervera R, et al. International consensus statement on an update of the classification criteria for definite antiphospholipid syndrome (APS). J. Thromb. Haemost. 2006;4(2):295-306.

3- Antovic A, Sennström M, Bremme K, Svenungsson E. Obstetric antiphospholipid syndrome. Lupus Sci. \&amp;amp; Med. 2018;5(1): e000197.

4- Reyes Llerena GA, Guibert Toledano M, Álvarez Villanueva RR, Núñez Hernández Néstor J, Vasallo Prieto R. Controversias del síndrome de anticuerpos antifosfolipídicos en obstetricia. Reumatol. Clínica. 2017;13(1):30-36.

5- Out HJ, Kooijman CD, Bruinse HW, Derksen RHWM. Histopathological findings in placentae from patients with intra-uterine fetal death and anti-phospholipid antibodies. Eur. J. Obstet. Gynecol. Reprod. Biol. 1991;41(3):179-186.

6- Van Horn JT, Craven C, Ward K, Branch DW, Silver RM. Histologic features of placentas and abortion specimens from women with antiphospholipid and antiphospholipis-like syndromes. Placenta. 2004;25(7):642-648.

7- Redline RW. Classification of placental lesions. Am. J. Obstet. Gynecol. 2015;213(4):S21-S28.

8- Martinelli I, Ruggenenti P, Cetin I, Pardi G, Perna A, Vergani P, et al. Heparin in pregnant women with previous placenta-mediated pregnancy complications: a prospective, randomized, multicenter, controlled clinical trial. Blood. 2012;119(14):3269-75.

9- Faye-Petersen OM, Ernst LM. Maternal Floor Infarction and Massive Perivillous Fibrin Deposition. Surg. Pathol. Clin. 2013;6(1):101-114.

10- Viall CA, Chamley LW. Histopathology in the placentae of women with antiphospholipid antibodies: A systematic review of the literature. Autoimmun. Rev. 2015;14(5):446-471.

11- Redline RW, Ravishankar S. Fetal vascular malperfusion, an update. APMIS. 2018;126(7):561-569.

12- Heider A. Fetal vascular malperfusion. Arch. Pathol. Lab. Med. 2017;141(11):1484-1489.

13- Gogia N, Machin GA. Maternal thrombophilias are associated with specific placental lesions. Pediatr. Dev. Pathol. 2008;11(6):424-429.

14- Arias F, Romero R, Joist H, Kraus FT. Thrombophilia: a mechanism of disease in women with adverse pregnancy outcome and thrombotic lesions in the placenta. J. Matern. Fetal. Med. 7(6):277-86.

15- Mousa HA, Alfirevic1 Z. Do placental lesions reflect thrombophilia state in women with adverse pregnancy outcome? Hum. Reprod. 2000;15(8):1830-3.

16- Rodger MA, Betancourt MT, Clark P, et al. The association of factor V leiden and prothrombin gene mutation and placenta-mediated pregnancy complications: A systematic review and meta-analysis of prospective cohort studies. PLoS Med. 2010;7(6):e1000292.

17- Beeksma FA, Erwich JJHM, Khong TY. Placental fetal vascular thrombosis lesions and maternal thrombophilia. Pathology. 2012;44(1):24-28.

\section{Aporte de cada autor al trabajo}

Juan Zunino: Concepción y diseño del trabajo, recolección de datos, redacción y revisión crítica del manuscrito. 